\title{
Still birth in a tertiary health facility in Enugu state South-East Nigeria: a hidden tragedy
}

\author{
Hope O. Nwoga ${ }^{1 *}$, Miriam O. Ajuba², Chukwuma P. Igweagu²
}

\begin{abstract}
${ }^{1}$ Department of Community Medicine, Enugu State University Teaching Hospital Parklane, Enugu, Nigeria
${ }^{2}$ Department of Community Medicine, Enugu State University College of Medicine, Enugu, Nigeria
\end{abstract}

Received: 29 April 2021

Accepted: 28 May 2021

\section{*Correspondence:}

Dr. Hope O. Nwoga,

E-mail: nwogahope@gmail.com

Copyright: (C) the author(s), publisher and licensee Medip Academy. This is an open-access article distributed under the terms of the Creative Commons Attribution Non-Commercial License, which permits unrestricted non-commercial use, distribution, and reproduction in any medium, provided the original work is properly cited.

\section{ABSTRACT}

Background: Stillbirth is one of the common adverse outcomes of pregnancy that occur worldwide. The prevalence differs in different continents of the world and even within different localities in the same country. The objective of this study was to determine the prevalence and social determinants of health that affect still birth in Enugu state, Nigeria.

Methods: The study was a prospective hospital-based study conducted at the obstetrics and gynecology department of a tertiary health facility in Nigeria. All the data were retrieved from the ante natal and delivery card of all the women that delivered at the unit within the time of data collection. Data was analyzed using SPSS version 25 and variables were presented as frequencies, percentages, means, and standard deviation. Bivariate analysis was done using chi-square test. The level of significance was set at $p$ value $\leq 0.05$.

Results: The mean age of the mothers was $29.76 \pm 4.69$ while most of them were aged 21-30 years 431(56.0\%). Majority of them were employed $529(68.7 \%)$ and had tertiary education $484(62.9 \%)$. The prevalence of still birth was 40.3 per 1000 births. Maternal age, marital status, educational levels and booking status affected the prevalence of still birth. On logistic regression, un-booked mothers had 25 times odds of having still birth when compared to those that booked after 28 weeks gestation

Conclusions: The prevalence of still birth is high in Enugu state with un-booked mothers contributing about $88.6 \%$. Early booking helps to detect possible complications early with timely interventions.

Keywords: Nigeria, Pregnancy outcome, Prevalence, Still birth

\section{INTRODUCTION}

Stillbirth is a common adverse outcome of pregnancy worldwide. ${ }^{1}$ The WHO defines stillbirth as a baby born with no signs of life at or after 28 weeks gestation. ${ }^{2}$ Globally in 2015, 2.6 million third trimester stillbirths occurred and most of these were in Low- and middleincome countries (LMICs), three quarters in South Asia and Sub-Saharan Africa. ${ }^{3}$ The third trimester stillbirth rate in South Asia and sub-Saharan Africa is approximately 10 times that of developed countries (29 vs 3 per 1000 births). ${ }^{3}$

Only ten countries carry the burden of over 65 per cent of the total stillbirths in the world and Nigeria was ranked second highest among them (after Pakistan) with an estimated 313,700 stillbirths (42.9 per 1,000 total births). ${ }^{3}$ This accounts for $12.2 \%$ of the estimated 2.6 million global stillbirths showing that Nigeria still contributes to the global burden of stillbirths. ${ }^{3}$ Globally, from 1995 to 2009 , the stillbirth rate declined by $14.0 \%$, representing a $1.1 \%$ decrease per year, however, this improvement mainly occurred in developed countries, rather than in developing countries. $^{4,5}$

The risk factors for still birth may vary by country depending upon the availability of resources for provision of care, as well as access to care by remotely located populations. ${ }^{3}$ The prevalence of stillbirth however, varies between localities even in a particular country. In Nigeria, 
the prevalence of stillbirth varied from as low as 23 per 1000 deliveries in South-East Nigeria, 39 per 1000 deliveries in South-South Nigeria and as high as 48 per 1000 deliveries in Northern Nigeria. ${ }^{6}$ This variation may be attributed to differences in the availability of health facilities as well as cultural differences among different ethnic groups. There are several common risk factors for stillbirth in developing and developed countries and these tend to relate to each other. ${ }^{7}$ They include lack of education of women, low socio-economic status, and the inability to make timely decisions about seeking care, advanced or young maternal age( $>35$ years or $<20$ years), lack of awareness about danger signs, delay in moving to a hospital, non-availability of community resources, and poor maternal nutritional status. ${ }^{8,9}$ Maternal and foetal medical conditions and the poor response of the health care system to these conditions act as proximal risk factors for stillbirth.

Poverty and low educational status can also affect a family's decisions about seeking care such as identifying danger signs, and accessing antenatal, delivery, or emergency care. In many resource-poor countries, even when women may reach a facility in time for a potentially life-saving intervention, inadequately prepared facilities may fail to prevent adverse maternal or foetal outcomes. ${ }^{10}$ Even though recent global analyses suggest a $25.5 \%$ overall decline in stillbirth rates over the last 5 years, large variations in stillbirth rates exist between and within LMIC, and many LMICs have experienced little if any reduction in stillbirths. ${ }^{11,12}$ Stillbirths involve loss of life and thus can be viewed as a tragic situation for the parents. Thus, many parents face psychological problems after stillbirth, including anxiety and depression, post-traumatic stress disorder, and stigmatization. ${ }^{13}$ Studies have also shown that women who have experienced stillbirth are more likely to experience it again in later pregnancies. ${ }^{14}$ Hence, preventing stillbirth is an important way of achieving the Global Every Newborn Action Plan by the 67th WHO Assembly target of 12 or fewer stillbirths per 1000 births in every country by $2035 .{ }^{15}$ Also most developing countries including Nigeria lack adequate knowledge on the various factors that affect still birth.

The aim of the study was to determine the prevalence of stillbirth and identify the maternal socio-demographic characteristics associated with stillbirth among mothers who delivered at a tertiary health facility in Enugu state, South-East Nigeria. The result of the study will help in developing appropriate policies and strategies that will help to control stillbirth in the State and the country generally.

\section{METHODS}

\section{Study area}

The study was carried out at the obstetrics and gynecology department of Enugu State University Teaching Hospital (ESUTH) Park Lane Enugu. ESUTH is one of the tertiary health facilities in Enugu State, Nigeria that provides tertiary services for patients within the state and neighboring states. It also serves as a referral center for both the government and privately-owned health facilities within and outside the state. It is located within the Enugu Metropolis.

\section{Study design}

This was a prospective hospital-based study.

\section{Study population}

All the women that delivered at the O\&G Department of ESUTH Park Lane Enugu within the time of data collection (1July 2020- 31 January 2021) were included in the study.

\section{Inclusion criteria}

Women who delivered at a gestational age of $\geq 28$ weeks were included.

\section{Exclusion criteria}

Women whose data on gestational age were missing were excluded for the study.

\section{Data collection methods}

Data was collected for a period of 7 months (1 July 202031 January 2021). Two trained research assistants were used to collect the data. Each day they collect data on the previous day's delivery from the mother's delivery cards.

This was done to avoid loss of patient's card and information that may be encountered if cards are left for longer periods. The information extracted were entered into a structured pro forma which was divided into sections which included maternal socio-demographic characteristics and obstetric history.

\section{Data management}

\section{Independent variable}

Socio-demographic characteristics and obstetric history were independent variable.

\section{Dependent variables}

Still birth was dependent variable.

\section{Statistical analysis}

All the data were imputed into SPSS version 25 and edited for errors by generating frequencies. Categorical variables were summarized using frequencies and percentages. Chisquared test was used to test for associations between 
socio-demographic characteristics and obstetric history and still birth with significant level placed at $p$ value $\leq 0.05$.

All the variables that had $p<0.2$ on the bivariate analysis were imputed for multivariate logistic regression.

Odds ratio together with their corresponding $\mathrm{p}$ values and confidence intervals were computed based on a two tailed test and performed at the $5 \%$ error rate.

\section{RESULTS}

Table 1 shows the socio-demographic and obstetric history of the women. The mean age of the women was 29.76 44.69 while most of them were aged 21-30 years 431 (56.0\%). Majority were married 746 (96.9\%), Igbos 763 (99.1) and Christians 766 (99.5\%). About a third of them were unemployed $241(31.3 \%)$. Majority of them 484 $(62.9 \%)$ had tertiary education.

Table 1: Socio-demographic characteristics of the women that delivered at tertiary health facility.

\begin{tabular}{|c|c|c|}
\hline Variables & Frequency & Percentage $(\%)$ \\
\hline \multicolumn{3}{|l|}{ Age in years } \\
\hline Mean \pm SD & $29.76 \pm 4.69$ & \\
\hline \multicolumn{3}{|l|}{ Age groups (years) } \\
\hline$\leq 20$ & 14 & 1.8 \\
\hline $21-30$ & 431 & 56.0 \\
\hline $31-40$ & 318 & 41.3 \\
\hline $41-50$ & 7 & 0.9 \\
\hline \multicolumn{3}{|l|}{ Marital status } \\
\hline Married & 746 & 96.9 \\
\hline Single & 24 & 3.1 \\
\hline \multicolumn{3}{|l|}{ Ethnicity } \\
\hline Igbo & 763 & 99.1 \\
\hline Others & 7 & 0.9 \\
\hline \multicolumn{3}{|l|}{ Religion } \\
\hline Christianity & 766 & 99.5 \\
\hline Islam & 4 & 0.5 \\
\hline \multicolumn{3}{|l|}{ Employment } \\
\hline Employed & 529 & 68.7 \\
\hline Unemployed & 241 & 31.3 \\
\hline \multicolumn{3}{|l|}{ Educational level } \\
\hline Tertiary & 484 & 62.9 \\
\hline Secondary completed & 281 & 36.5 \\
\hline Primary completed & 5 & 0.6 \\
\hline \multicolumn{3}{|l|}{ Parity } \\
\hline $1-2$ & 531 & 69.0 \\
\hline $2-4$ & 196 & 25.6 \\
\hline$\geq 5$ & 43 & 5.4 \\
\hline \multicolumn{3}{|l|}{ Complications } \\
\hline Yes & 368 & 47.8 \\
\hline No & 402 & 52.2 \\
\hline Anaemia (booking) & $\mathrm{N}=628$ & \\
\hline Yes & 158 & 25.2 \\
\hline No & 470 & 74.8 \\
\hline Anaemia (delivery) & $\mathrm{N}=757$ & \\
\hline Yes & 303 & 40.0 \\
\hline No & 454 & 60.0 \\
\hline Booking gestational age & $\mathrm{N}=770$ & \\
\hline Un-booked & 146 & 19.0 \\
\hline$\leq 13$ weeks & 61 & 7.9 \\
\hline $14-28$ weeks & 415 & 53.9 \\
\hline$\geq 28$ weeks & 148 & 19.2 \\
\hline Still birth & $\mathrm{N}=770$ & \\
\hline Yes & 31 & 4.0 \\
\hline No & 739 & 96.0 \\
\hline
\end{tabular}


Table 2 shows the factors that affected the prevalence of still birth among the studied women. Maternal age $\left(x^{2}=13.558, \mathrm{p}=0.004\right)$, marital status $\left(x^{2}=10.244, \mathrm{p}=0.001\right)$ booking status $\left(x^{2}=72.224, \mathrm{p} \leq 0.001\right)$ and educational levels $\left(x^{2}=16.608, p<0.001\right)$ affected the prevalence of still birth.
From Table 3 only booking status of the mothers predicted still birth. Un-booked mothers had 25 times odds of having still birth when compared to those that booked after 28 weeks gestation.

Table 2: Bivariate analysis to determine factors that affected still birth.

\begin{tabular}{|c|c|c|c|c|}
\hline \multirow{2}{*}{ Variables } & \multicolumn{2}{|l|}{ Still birth } & \multirow{2}{*}{$x^{2}$} & \multirow{2}{*}{ P value } \\
\hline & No & Yes & & \\
\hline \multicolumn{5}{|l|}{ Age groups in years } \\
\hline$\leq 20$ & $11(78.6)$ & $3(21.4)$ & 13.558 & $0.004 *$ \\
\hline $21-30$ & $417(96.8)$ & $14(3.2)$ & & \\
\hline $31-40$ & $305(95.9)$ & $13(4.1)$ & & \\
\hline$\geq 41$ & $6(85.7)$ & $1(14.3)$ & & \\
\hline \multicolumn{5}{|l|}{ Marital status } \\
\hline Married & $719(96.4)$ & $27(3.6)$ & 10.244 & $0.001 *$ \\
\hline Single & $20(83.3)$ & $4(16.7)$ & & \\
\hline \multicolumn{5}{|l|}{ Ethnicity } \\
\hline Igbo & $732(95.9)$ & $31(4.1)$ & 0.296 & 0.961 \\
\hline Yoruba & $1(100)$ & $0(0.0)$ & & \\
\hline Hausa & $5(100)$ & $0(0.0)$ & & \\
\hline Others & $1(100)$ & $0(0.0)$ & & \\
\hline \multicolumn{5}{|l|}{ Religion } \\
\hline Christianity & $734(95.9)$ & $31(4.1)$ & 0.211 & 0.900 \\
\hline Islam & $4(100)$ & $0(0.0)$ & & \\
\hline \multicolumn{5}{|l|}{ Employment } \\
\hline Employed & $505(95.5)$ & $24(4.5)$ & 1.142 & 0.285 \\
\hline Unemployed & $234(97.1)$ & $7(2.9)$ & & \\
\hline \multicolumn{5}{|l|}{ Educational level } \\
\hline Tertiary & $475(98.1)$ & $9(1.9)$ & 16.608 & $<0.001^{*}$ \\
\hline Secondary completed & $259(259)$ & $22(7.8)$ & & \\
\hline Primary completed & $5(100)$ & $0(0.0)$ & & \\
\hline \multicolumn{5}{|l|}{ Parity } \\
\hline $1-2$ & $508(95.7)$ & $23(4.3)$ & 2.201 & 0.333 \\
\hline $3-4$ & $191(97.4)$ & $5(2.6)$ & & \\
\hline$>4$ & $40(93.0)$ & $3(7.0)$ & & \\
\hline \multicolumn{5}{|l|}{ Complications } \\
\hline Yes & $353(95.9)$ & $15(4.1)$ & 0.005 & 0.946 \\
\hline No & $386(96.0)$ & $16(4.0)$ & & \\
\hline \multicolumn{5}{|l|}{ Anaemia (booking) } \\
\hline Yes & $151(95.6)$ & $7(4.4)$ & 0.213 & 0.645 \\
\hline No & $453(96.4)$ & $17(3.6)$ & & \\
\hline Anaemia (delivery) & $\mathrm{N}=757$ & & & \\
\hline Yes & $291(96.0)$ & $12(4.0)$ & 0.000 & 0.998 \\
\hline No & $436(96.0)$ & $18(4.0)$ & & \\
\hline \multicolumn{5}{|l|}{ Booking status } \\
\hline Un-booked & $122(83.6)$ & $24(16.4)$ & 72.224 & $<0.001 *$ \\
\hline Booked $\leq 13$ weeks & $61(100)$ & $0(0.0)$ & & \\
\hline Booked 14-28 weeks & $409(98.6)$ & $6(1.4)$ & & \\
\hline Booked after 28 weeks & $147(99.3)$ & $1(0.7)$ & & \\
\hline
\end{tabular}


Table 3: Logistic regression to determine the predictors of still birth.

\begin{tabular}{|c|c|c|c|c|}
\hline \multirow{2}{*}{ Variables } & \multirow{2}{*}{ Odds ratio } & \multirow{2}{*}{ P value } & \multicolumn{2}{|c|}{ 95\% CI for odds ratio } \\
\hline & & & Lower & Upper \\
\hline \multicolumn{5}{|l|}{ Age groups (years) } \\
\hline$\leq 20$ & 0.778 & 0.861 & 0.047 & 12.916 \\
\hline $21-30$ & 0.184 & 0.133 & 0.020 & 1.675 \\
\hline $31-40$ & 0.199 & 0.155 & 0.022 & 1.837 \\
\hline$\geq 41$ & 1 & & & \\
\hline \multicolumn{5}{|l|}{ Marital status } \\
\hline Married & 0.211 & 0.057 & 0.042 & 1.050 \\
\hline Single & 1 & & & \\
\hline \multicolumn{5}{|l|}{ Booking } \\
\hline Un-booked & 25.081 & 0.002 & 3.247 & 193.706 \\
\hline Booked $\leq 13$ weeks & 0.812 & 0.997 & 0.040 & 7.789 \\
\hline Booked 14-28 weeks & 2.263 & 0.452 & 0.269 & 19.043 \\
\hline Booked after 28 weeks & 1 & & & \\
\hline
\end{tabular}

\section{DISCUSSION}

The prevalence of still birth in this study was 40.3 per 1000 deliveries. This is comparable to the Nigeria prevalence placed at 42.9/1000 deliveries but high when compared to the documented prevalence in South Eastern Nigeria (23/1000 deliveries) where the study was conducted. ${ }^{6,16}$ This may be explained by the fact that the present health facility is a referral centre where complicated cases are managed most of which result in still birth. This prevalence is also higher than the report of another Nigerian study conducted among women that delivered at the primary and secondary health facilities, but lower than the report of a similar study in Nepal. ${ }^{17,18}$ The differences here, may be due to differences in antenatal services at the health facilities studied and the availability and accessibility of health care in these localities.

Still birth was found to be more among younger mothers aged $\leq 20$ years followed by those aged $\geq 41$ years. This was similar to what was reported in a multi facility study in Nigeria where the prevalence of still birth was found to be higher at extremes of maternal reproductive ages. ${ }^{17}$ This was not surprising as pregnancies occurring at extremes of female reproductive ages are high-risk pregnancies for both mothers and new-borns. Furthermore, older women have had more pregnancies with each having its own risk. Childbearing mothers belonging to these extremes of age have a higher risk of experiencing pregnancy-induced hypertension or gestational diabetes and this place them at greater risk of stillbirth. ${ }^{19}$

However, a study in Nepal reported that still birth was more among older women and lower among younger mothers. ${ }^{18}$ Other studies reported that increasing maternal age was a significant risk factor for still birth..$^{20,21}$

Single mothers had more still birth than married mothers from our study. Most married mothers will have the support of their husbands both financially and emotionally during pregnancy and this will influence their booking status which has been shown to affect still birth. ${ }^{22}$ Also most single mothers are at the extreme of maternal age ( $\leq 20$ years) which is also a risk factor for still birth. ${ }^{17}$

Employment status of the mother was not significantly associated with still birth but employed women had a higher prevalence of still birth when compared to the unemployed. This may be explained by the kind of work these mothers engaged in, as occupations that involves long standing and working in extremely hot environments have been shown to result in adverse pregnancy outcomes including still birth. ${ }^{23}$ Other studies contradict this finding and reported that unemployed women had higher prevalence of still birth. ${ }^{17,24}$

Our study found out that the rate of still birth was more among women with secondary education compared to women with primary education. This was surprising as higher educational level was supposed to be protective of still birth as better educated women are better equipped to take care of themselves during pregnancy.

However, it is worthy of note that while education is expected to reduce ignorance among women and increase their use of health care services including antenatal care but mothers who had only secondary education may be hindered by lack of employment since those with tertiary education do not find it easy to secure a good job especially in Nigeria where the rate of unemployment is high, not to mention those with only secondary education. Hence this 'half-baked education' can hinder them from acquiring skills that will help them become self-employed to afford adequate antenatal care. Women with only primary education know that they have a slimmer chance of securing a white-collar job and therefore learn a skill early to have financial freedom and become economically more empowered than their counterparts with secondary education who may rarely secure a white-collar job.

Also, the fact that mothers with only primary education had a lower prevalence of stillbirth than mothers with only secondary education suggest that apart from education, there may be other factors which could include economic 
empowerment. A similar study corroborated our findings. ${ }^{17}$ Other studies however, contradicts the findings of our study reporting that still birth was higher among less educated women. ${ }^{18,23,25,26}$ Other studies have also shown that stillbirth was higher in women with no formal education with the rate of stillbirth decreasing with increasing educational status. ${ }^{27,28}$ These may be attributed to unemployment and lack of prenatal care during pregnancy.

Surprisingly, our study showed that there was no significant difference in the proportion of stillbirth by mothers of varied parity. This contradicts literature assertions that stillbirth is associated with multi parity. ${ }^{28,29}$

From our study, there was no significant association between still birth and having complications in pregnancy. However, it has been shown in literature that mothers with complications are at higher risk of stillbirth than mothers without complications. ${ }^{30}$

Our study found out that booking for antenatal and at an early stage has a significant influence on still birth. Unbooked women had 25 times odds of having still birth when compared to those that booked after 28 weeks gestation. A similar study however observed that unbooked primi-parous and multiparous women experienced more stillbirths as a result of not booking or nonattendance at antenatal care during pregnancy. ${ }^{22}$ Therefore parity alone is not enough to predict stillbirth, other maternal factors such as attendance to antenatal clinic are capable of influencing pregnancy outcome.

\section{Limitations}

The limitations of the study include the fact that it is a hospital-based study in a country where most deliveries occur outside of health facilities. Thus, the prevalence of still birth deliveries could be significantly different from its prevalence in the general population.

Also, since the hospital is a tertiary health facility with many complicated obstetric cases referred to it, there could be over-estimation of still birth deliveries.

\section{CONCLUSION}

The prevalence of stillbirth is high in the study area. Mothers' age, marital status and booking significantly influenced the prevalence of stillbirth among the mothers. This therefore, highlights the need for facility-based public health interventions to help reduce the occurrence of stillbirths among women attending these health facilities.

\section{Recommendations}

Female empowerment should be given more attention in government health facilities to enable women seek and obtain necessary care during pregnancy and delivery. Health resources should be available in health facilities to equip them handle complicated cases with poor outcome such as stillbirths.

\section{ACKNOWLEDGMENTS}

The authors acknowledge the research assistants that collected the data and the nurse in charge of the labour room for her assistance.

Funding: No funding sources

Conflict of interest: None declared

Ethical approval: The study was approved by the Institutional Ethics Committee

\section{REFERENCES}

1. Ouyang F, Zhang J, Betran AP, Yang Z, Souza JP, Merialdi M. Recurrence of adverse perinatal outcomes in developing countries. Bull World Health Organ. 2013;91(5):357-67.

2. WHO. International Classification of Disease 10th Revision (ICD-10) 2010, 2021. Available at: http://www.who.int/classifications/icd/ICD10Volum e2_en_2010.pdf?ua-1. Accessed on 12 April 2021.

3. Lawn JE, Blencowe H, Waiswa P, Amouzou A, Mathers C, Hogan D, Flenady V, et al. Stillbirths: rates, risk factors, and acceleration towards 2030. Lancet. 2016;387(10018):587-603.

4. Cousens S, Blencowe H, Stanton C, Chou D, Ahmed $\mathrm{S}$, Steinhardt L, et al. National, regional, and worldwide estimates of stillbirth rates in 2009 with trends since 1995: a systematic analysis. Lancet. 2011;377(9774):1319-30.

5. Clure EM, Pasha O, Goudar SS, Chomba E, Garces A, Tshefu A, Althabe F, et al. Epidemiology of stillbirth in low-middle income countries: a Global Network Study. Acta Obstet Gynecol Scand. 2011;90(12):1379-85.

6. Tukur D, Alhaji AA. Stillbirth in Nigeria: Rates and Risk factors based on 2013 Nigeria DHS. Open Access Library J. 2016;3:1-12.

7. Goldenberg RL, Saleem S, Pasha O, Harrison MS, Mcclure EM. Reducing stillbirths in low-income countries. Acta Obstet Gynecol Scand. 2016;95(2):135-43.

8. Aminu M, Unkels R, Mdegela M, Utz B, Adaji S, Broek N. Causes of and factors associated with stillbirth in low- and middle-income countries: a systematic literature review. BJOG. 2014;121(4):14153.

9. Flenady V, Koopmans L, Middleton P, Froen JF, Smith GC, Gibbons K, et al. Major risk factors for stillbirth in high-income countries: a systematic review and meta-analysis. Lancet. 2011; 377(9774):1331-40.

10. Manasyan A, Saleem S, Koso TM, Althabe F, Pasha O, Chomba E, Goudar SS, et al. Assessment of obstetric and neonatal health services in developing country health facilities. Am J Perinatol. 2013;30(9):787-94. 
11. Lawn JE, Blencowe H, Pattinson R, Cousens $S$, Kumar R, Ibiebele I, et al. Stillbirths: Where? When? Why? How to make the data count?. Lancet. 2011;377(9775):1448-63.

12. Blencowe H, Cousens S, Jassir FB, Say L, Chou D, Mathers C, Hogan D, et al. National, regional, and worldwide estimates of stillbirth rates in 2015, with trends from 2000: a systematic analysis. Lancet Glob Health. 2016;4(2):98-108.

13. Turton P, Evans C, Hughes P. Long-term psychosocial sequelae of stillbirth: phase II of a nested case-control cohort study. Arch Womens Ment Health. 2009;12(1):35-41.

14. Lamont K, Scott NW, Jones GT, Bhattacharya S. Risk of recurrent stillbirth: systematic review and metaanalysis. BMJ. 2015;350:3080.

15. WHO. Every newborn: an action plan to end preventable deaths, 2014. Available at: https://www.who.int/maternal_child_adolescent/docu ments/every-newborn-action-plan/en/. Accessed on 10 April 2021.

16. UNICEF. Hidden tragedy: Nigeria accounts for one of the highest stillbirth rates in Africa, 2020. Available at: https://www.unicef.org.nigeria/stories/hiddentragedy-nigeria-accounts-one-highest-stillbirth-ratesafrica. Accessed on 16 April 2021.

17. Anyichie NE, Nwagu EN. Prevalence and maternal socio-demographic factors associated with stillbirth in health facilities in Anambra, South-East Nigeria. Afr Health Sci. 2019;19(4):3055-62.

18. Bhusal M, Gautam N, Lim A, Tongkumchum P. Factors Associated With Stillbirth Among Pregnant Women in Nepal. J Prev Med Public Health. 2019;52(3):154-60.

19. WHO, UNICEF, UNFPA, World Bank Group, UN Population Division. Trends in Maternal Mortality: 1990 to 2015, 2015. Available at http://apps.who.int/iris/bitstream/10665/194254/1/97 89241565141_eng.pdf?ua=1. Accessed on 21 March 2021.

20. Ashish KC, Nelin V, Wrammert J, Ewald U, Vitrakoti R, Baral GN, Malqvist M. Risk factors for antepartum stillbirth: a case-control study in Nepal. BMC Pregnancy Childbirth. 2015;15:146.
21. Asiki G, Baisley K, Newton R, Marions L, Seeley J, Kamali A, Smedman L. Adverse pregnancy outcomes in rural Uganda (1996-2013): trends and associated factors from serial cross sectional surveys. BMC Pregnancy Childbirth. 2015;15:279.

22. Igwegbe AO, Nwosu BO, Ugboaja JO, Monago NE. Stillbirth in a Nigerian Tertiary Hospital. Nigerian Med J. 2008; 49:74-8.

23. Lofwander M. Stillbirths and associations with maternal education. A registry study from a regional hospital in north eastern Tanzania. Epidemiol Commun Health. 2012;66(7):240-6.

24. Alhassan A, Ayikai LA, Alidu H, Yakong VN. Stillbirth and associated factors in a Peri-urban District in Ghana. J Med Biomed Sci. 2016;5(1):2331.

25. Auger N, Delezire P, Harper S, Platt RW. Maternal education and stillbirth: estimating gestational-agespecific and cause-specific associations. Epidemiology. 2012;23(2):247-54.

26. Clure EM, Saleem S, Goudar SS, Moore JL, Garces A, Esamai F, et al. Stillbirth rates in low-middle income countries 2010- 2013: a population-based, multi-country study from the Global Network. Reprod Health. 2015;12(2):7.

27. Ugwa EA, Ashimi A. An assessment of stillbirths in a tertiary hospital in northern Nigeria. J Matern Fetal Neonatal Med. 2015;28(13):1585-8.

28. Mutihir JT, Eka PO. Stillbirths at the Jos University Teaching Hospital: incidence, risk, and etiological factors. Niger J Clin Pract. 2011;14(1):14-8.

29. Silver RM, Varner MW, Reddy U, Goldenberg R, Pinar H, Conway D, et al. Work-up of stillbirth: a review of the evidence. Am J Obstet Gynecol. 2007;196(5):433-44.

30. Goldenberg RL, Clure EM, Bann CM. The relationship of intrapartum and antepartum stillbirths rates to measures of obstetric care in developed and developing countries. Acta obstetricia et gynecologica Scandinavica. 2007;86:1303-9.

Cite this article as: Nwoga $1 \mathrm{HO}$, Ajuba MO, Igweagu CP. Still birth in a tertiary health facility in Enugu state South-East Nigeria: a hidden tragedy. Int J Reprod Contracept Obstet Gynecol 2021;10:258490. 